\title{
Characteristics of New Biologic Users Among the Moderate-to-Severe Psoriasis Population- Retrospective Cohort Study Leveraging the Modernizing Medicine Data Services Database
}

Timothy Fitzgerald $\cdot$ Aimee M. Near $\cdot$ Hyunchung Kim $\cdot$
Amanda Teeple $\cdot$ Mobolaji Olurinde $\cdot$ Katelyn Rowland

Received: November 8, 2021 / Accepted: February 8, 2022 / Published online: February 24, 2022

(C) The Author(s) 2022

\section{ABSTRACT}

Introduction: Biologics have expanded the treatment options in the management of patients with moderate-to-severe psoriasis. The objective of this study was to describe patient characteristics and previous treatments in psoriasis patients newly treated with guselkumab, secukinumab, or ixekizumab.

Methods: This retrospective study included patients $\geq 18$ years old with psoriasis in the USA who were newly treated with guselkumab, secukinumab, or ixekizumab between 1 July 2017 and 31 March 2019 in the Modernizing Medicine Data Services database (MMDS). Patients were indexed on their first prescription or injection record of guselkumab, secukinumab, or ixekizumab, and three mutually exclusive cohorts were created. Patients were required to have evidence of moderate-to-severe psoriasis, defined as Physician Global Assessment (PGA) score of 3 or 4 , or body surface area

T. Fitzgerald · A. Teeple $\cdot$ M. Olurinde $\cdot$ K. Rowland Janssen Scientific Affairs, LLC, Titusville, NJ, USA

A. M. Near $(\bowtie) \cdot$ H. Kim

Real World Evidence Solutions, IQVIA, 4280

Emperor Blvd, Durham, NC 27703, USA

e-mail: Aimee.Near@iqvia.com
$(B S A) \geq 10 \%$ on index date or within 12 months before index. Baseline characteristics, including treatment history, were reported for each cohort.

Results: The study population included 461 guselkumab, 619 secukinumab, and 375 ixekizumab patients. The median age across cohorts was 51-52 years. Median baseline BSA ranged from $15 \%$ to $20 \% ; 16.1-29.3 \%$ of patients had a PGA of 4 and over half of patients were obese prior to index. Approximately $40 \%$ of patients had comorbid cardiovascular disease and $20.8-24.2 \%$ of patients had a psychiatric disorder. About half of patients in each cohort had prior biologic use, of which adalimumab was most common (28.2-34.9\%) across the cohorts. Conclusion: This real-world study describes the characteristics of patients with moderate-tosevere psoriasis receiving biologic treatments.

Keywords: Biologics; Body surface area; Electronic medical record; Guselkumab; Ixekizumab; Modernizing medicine data services; Physician global assessment; Psoriasis; Real-world; Secukinumab 


\section{Key Summary Points}

\section{Why carry out this study?}

Efficacy of biologics in management of patients with moderate-to-severe psoriasis is well established in clinical trials; however, there is limited evidence on the use of these medications in real-world settings.

The objective of the current study was to describe the demographic and clinical characteristics and prior treatment of patients with moderate-to-severe psoriasis, newly initiated on three biologics approved for this indication: guselkumab, secukinumab, and ixekizumab.

\section{What was learned from the study?}

The results suggest that over $80 \%$ of patients treated with these biologics are overweight or obese, and approximately $40-50 \%$ are current or past smokers. Correspondingly, a high prevalence of cardiovascular disease was observed. About half of patients in each cohort had prior biologic use.

\section{INTRODUCTION}

Psoriasis is an immune-mediated, chronic inflammatory disease, affecting approximately 7.4 million adults in the USA, with an estimated prevalence of $2-4 \%[1,2]$. In the majority of patients with psoriasis, skin involvement is the only detectable manifestation of the disease; nevertheless, consideration of the condition as a chronic, multisystem inflammatory disease is crucial to achieve an optimal therapeutic approach [3]. Plaque psoriasis is the most prevalent type of the disease and is characterized by the presence of erythematous plaques $[1,4]$.
Psoriasis is a systemic disease affecting different organ systems [4], and is associated with increased incidence of comorbid conditions including psoriatic arthritis, Crohn's disease, metabolic syndrome, depression, cancer, and cardiovascular disease [5]. Moreover, evidence suggests that obesity may be a risk factor for the development of psoriasis [6] and, in turn, the prevalence of obesity is significantly higher in patients with moderate-to-severe psoriasis as compared with the general population [7]. Recent studies have shed light on the role of adipose tissue in psoriasis, with both obesity and psoriasis presenting proinflammatory states and cross-talk between adipocytes and the immune system [8].

With the advent of biologics, treatment of psoriasis has evolved and offered hope to patients with moderate-to-severe psoriasis who fail to respond or may not be satisfied with conventional regimens [9]. Biologics including tumor necrosis factor-alpha inhibitors (TNF- $\alpha$ ) (e.g., adalimumab, etanercept, infliximab, and certolizumab), interleukin (IL)-17 inhibitors (e.g., brodalumab, ixekizumab, secukinumab); IL-23 inhibitors (e.g., guselkumab, tildrakizumab, risankizumab), and IL-12/23 inhibitors (e.g., ustekinumab) have revolutionized the treatment of patients with moderate-to-severe psoriasis [3, 10]. Several clinical studies have reported superior efficacy and safety of biologics in the treatment of patients with psoriasis [11-13].

Although numerous clinical trials have established efficacy of biologics in patients with moderate-to-severe psoriasis [14-18], there is limited evidence on the use of these medications in real-world settings [2, 19-22]. The objective of this study was to describe the demographic and clinical characteristics, as well as prior treatment of patients with moderate-tosevere psoriasis, newly initiated on three biologics approved for this indication: guselkumab, secukinumab, and ixekizumab. 


\section{METHODS}

\section{Data Source}

This study leveraged data from the Modernizing Medicine Data Services (MMDS) database, a widely used dermatology-specific Electronic Medical Record (EMR) platform in the USA [23]. This national database includes over 1.2 million psoriasis patients across the USA.

This study was based on secondary, deidentified data that comply with the Health Insurance Portability and Accountability Act (HIPAA). Institutional review board approval was not required for this study.

\section{Study Population}

Adult patients ( $\geq 18$ years old) with psoriasis who were newly treated with guselkumab, secukinumab, or ixekizumab in MMDS between 1 July 2017 and 31 March 2019 (selection window) were included in the study. The index date for each patient was defined as the date of the earliest prescription or injection record of guselkumab, secukinumab, or ixekizumab during the selection window. Patients were required to have activity in the database before (minimum 6 months) and after (minimum 9 months) index, and evidence of moderate-tosevere psoriasis, defined as Physician Global Assessment (PGA) score of 3 or 4 (on a 0-4 scale) or body surface area (BSA) $\geq 10 \%$ on index date or within 12 months before index (i.e., baseline) [20, 22] (Fig. 1).

\section{Baseline Characteristics and Treatment History}

Patient demographics, clinical characteristics [e.g., body mass index (BMI), comorbidities, disease severity] and prior treatments were reported from the minimum 6-month baseline period. For demographics, BMI and disease severity, values on index or prior but closest to index date were reported. Prior treatments were defined as $\geq 1$ prescription or injection record of any of the following therapies prior to index (categories not mutually exclusive): topical treatments, including topical corticosteroids and other topical treatments (vitamin D analogs, calcineurin inhibitors, retinoids); phototherapy; systemic therapies, including systemic corticosteroids and other systemic
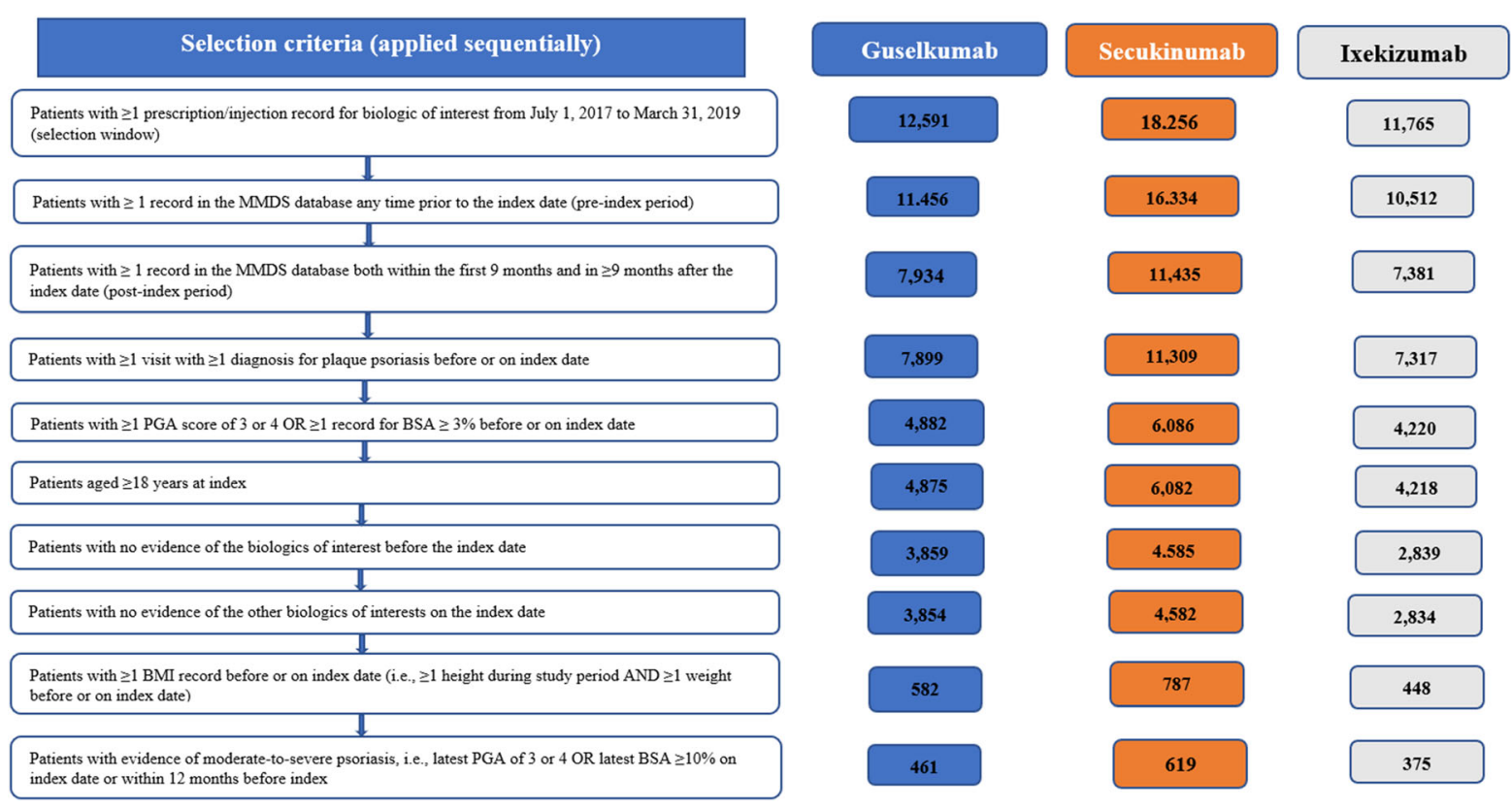

Fig. 1 Patient selection criteria and attrition of study cohorts 
therapies (apremilast, cyclosporine or acitretin, methotrexate); and biologics other than index treatment (adalimumab, etanercept, ustekinumab).

\section{Statistical Analysis}

Descriptive statistics were used to characterize patient demographics, clinical characteristics, and prior treatments. Cell counts with less than 5 patients were masked because of MMDS masking rules (i.e., all cells $<5$, including zero cells, must be masked and any additional cells until the sum of those cells is 5 or greater) for patient privacy. All analyses were conducted using SAS Release 9.4 (SAS Institute Inc., Cary, $\mathrm{NC}$ ).

\section{RESULTS}

\section{Population Characteristics}

Among the 12,591 guselkumab users in the database between 1 July 2017 and 31 March 2019, 461 met the inclusion criteria (Fig. 1). Six hundred nineteen out of 18,256 secukinumab users and 375 out of 11,765 ixekizumab users met the inclusion criteria and were included in the respective treatment cohorts. As presented in Table 1, the mean [standard deviation (SD)] age was 50.6 (13.8), 50.7 (14.8), and 50.7 (15.1) years for the guselkumab, secukinumab, and ixekizumab cohorts, respectively; median age was 51-52 years across cohorts. There was a fairly even distribution of male and female patients in the guselkumab and secukinumab cohorts, and a slightly higher proportion of males $(54.9 \%)$ in the ixekizumab cohort. The majority of patients (65.4-68.8\%) were white across the cohorts, with about one-quarter with unknown race information. Approximately half of patients were from the southeastern region of the USA $(57.3 \%$ in guselkumab cohort, $47.2 \%$ in secukinumab cohort, and $49.6 \%$ in ixekizumab cohort).

Over one-quarter of patients were overweight (BMI 25 to $\leq 29.9 \mathrm{~kg} / \mathrm{m}^{2}$ ) across the treatment cohorts $(29.1 \%$ in guselkumab cohort, $26.5 \%$ in secukinumab cohort, and $29.1 \%$ in ixekizumab cohort) and more than $50 \%$ of patients were obese (BMI $\geq 30 \mathrm{~kg} / \mathrm{m}^{2}$ ) (Table 1). Of guselkumab, secukinumab, and ixekizumab patients, $39.7 \%, 48.6 \%$, and $42.1 \%$ were current or past smokers, respectively. Cardiovascular disease was the most common comorbidity, afflicting $39.3-41.4 \%$ of patients, while $21.0-25.5 \%$ had musculoskeletal disease (osteoporosis or osteoarthritis). Metabolic diseases (18.4-20.0\%) and psychiatric disorders (20.8-24.2\%) were also common (Table 1 ).

Mean (SD) BSA was 23.1 (20.2), 22.3 (19.9), and 24.8 (19.6) for the guselkumab, secukinumab and ixekizumab cohorts, respectively; median baseline BSA ranged from $15 \%$ to $20 \%$ (Table 2). Baseline BSA values were available close to index (median days from pre-index BSA to index ranged from 5 to 12 days); $25 \%$ of patients had a BSA value recorded on index visit. The majority $(42.1-51.4 \%)$ of patients in each cohort had a baseline PGA score of 3; PGA of 4 was reported in $16.1-29.3 \%$ of patients across cohorts. Similar to BSA time from index, median days from pre-index PGA to index were low and ranged from 4 to 12 days.

\section{Prior Treatments}

Over $80 \%$ of patients in each cohort had prior topical corticosteroid use $(84.2 \%$ in guselkumab cohort, $86.8 \%$ in secukinumab cohort, $84.8 \%$ in ixekizumab) and $25.9-32.3 \%$ of patients had evidence of vitamin D analog use. Calcineurin inhibitor use (3.7-5.3\%) and retinoid use (1.3-1.9\%) were less common, as was phototherapy (8.2-12.6\%). Less than one-quarter (21.9-23.9\%) of patients had prior systemic corticosteroid use, while $18.4-21.0 \%$ of patients had methotrexate use; apremilast (9.3-13.2\%) and cyclosporine or acitretin use was low (3.2-5.3\%). Approximately half (47.5-55.1\%) of patients in each cohort had used biologics other than guselkumab, secukinumab, and ixekizumab prior to index, with prior use most frequent among guselkumab patients. Prior use of adalimumab was most common (28.2-34.9\%), followed by ustekinumab (16.2-32.5\%) and etanercept (10.6-14.2\%) (Fig. 2a and b). 
Table 1 Demographic and clinical characteristics of the patient population at baseline

\begin{tabular}{|c|c|c|c|c|c|c|}
\hline \multirow[t]{2}{*}{ Baseline characteristics } & \multicolumn{2}{|c|}{$\begin{array}{l}\text { Guselkumab } \\
\text { cohort }(n=461)\end{array}$} & \multicolumn{2}{|c|}{$\begin{array}{l}\text { Secukinumab } \\
\text { cohort }(n=619)\end{array}$} & \multicolumn{2}{|c|}{$\begin{array}{l}\text { Ixekizumab } \\
\text { cohort }(n=375)\end{array}$} \\
\hline & $\bar{n}$ & $\%$ & $\bar{n}$ & $\%$ & $\bar{n}$ & $\%$ \\
\hline \multicolumn{7}{|l|}{ Age, years } \\
\hline Mean (SD) & \multicolumn{2}{|l|}{$50.6(13.8)$} & \multicolumn{2}{|l|}{$50.7(14.8)$} & \multicolumn{2}{|l|}{$50.7(15.1)$} \\
\hline Median (IQR) & \multicolumn{2}{|l|}{$52.0(19)$} & \multicolumn{2}{|l|}{$51.0(22)$} & \multicolumn{2}{|l|}{$52.0(24)$} \\
\hline Min-Max & \multicolumn{2}{|l|}{$18-83$} & \multicolumn{2}{|l|}{$19-83$} & \multicolumn{2}{|l|}{$18-83$} \\
\hline \multicolumn{7}{|l|}{ Age category } \\
\hline $18-34$ years & 67 & 14.5 & 90 & 14.5 & 64 & 17.1 \\
\hline $35-39$ years & 38 & 8.2 & 59 & 9.5 & 36 & 9.6 \\
\hline $40-44$ years & 38 & 8.2 & 75 & 12.1 & 24 & 6.4 \\
\hline $45-54$ years & 124 & 26.9 & 130 & 21.0 & 90 & 24.0 \\
\hline $55-64$ years & 131 & 28.4 & 140 & 22.6 & 84 & 22.4 \\
\hline $65-74$ years & 44 & 9.5 & 94 & 15.2 & 61 & 16.3 \\
\hline 75 or older & 19 & 4.1 & 31 & 5.0 & 16 & 4.3 \\
\hline \multicolumn{7}{|l|}{ Gender } \\
\hline Male & 237 & 51.4 & 299 & 48.3 & 206 & 54.9 \\
\hline Female & 224 & 48.6 & 320 & 51.7 & 169 & 45.1 \\
\hline \multicolumn{7}{|l|}{ Race } \\
\hline White & 317 & 68.8 & 405 & 65.4 & 246 & 65.6 \\
\hline African American & 10 & 2.2 & 11 & 1.8 & 6 & 1.6 \\
\hline Asian & 12 & 2.6 & 15 & 2.4 & 6 & 1.6 \\
\hline Other & 14 & 3.0 & 29 & 4.7 & 13 & 3.5 \\
\hline Unknown & 108 & 23.4 & 159 & 25.7 & 104 & 27.7 \\
\hline \multicolumn{7}{|l|}{ Ethnicity } \\
\hline Hispanic or Latino & 28 & 6.1 & 46 & 7.4 & 17 & 4.5 \\
\hline Not Hispanic or Latino & 276 & 59.9 & 335 & 54.1 & 236 & 62.9 \\
\hline Unknown & 157 & 34.1 & 238 & 38.4 & 122 & 32.5 \\
\hline \multicolumn{7}{|l|}{ Geographic region } \\
\hline Northeast/unknown & 58 & 12.6 & 73 & 11.8 & 18 & 4.8 \\
\hline Midwest & 78 & 16.9 & 141 & 22.8 & 86 & 22.9 \\
\hline South & 264 & 57.3 & 292 & 47.2 & 186 & 49.6 \\
\hline West & 61 & 13.2 & 113 & 18.3 & 85 & 22.7 \\
\hline$B M I\left(\mathrm{~kg} / \mathrm{m}^{2}\right)^{a}$ & & & & & & \\
\hline
\end{tabular}


Table 1 continued

\begin{tabular}{|c|c|c|c|c|c|c|}
\hline \multirow[t]{2}{*}{ Baseline characteristics } & \multicolumn{2}{|c|}{$\begin{array}{l}\text { Guselkumab } \\
\text { cohort }(n=461)\end{array}$} & \multicolumn{2}{|c|}{$\begin{array}{l}\text { Secukinumab } \\
\text { cohort }(n=619)\end{array}$} & \multicolumn{2}{|c|}{$\begin{array}{l}\text { Ixekizumab } \\
\text { cohort }(n=375)\end{array}$} \\
\hline & $n$ & $\%$ & $n$ & $\%$ & $n$ & $\%$ \\
\hline Mean (SD) & $31.6(7.6)$ & & $32.0(7.6)$ & & $32.6(7.7)$ & \\
\hline Median (IQR) & $30.3(9)$ & & $30.7(9.9)$ & & $31.4(9.5)$ & \\
\hline Min-Max & $17.1-70.3$ & & $16.5-64.2$ & & $17.9-60.2$ & \\
\hline \multicolumn{7}{|l|}{ BMI category } \\
\hline$\leq 24.9 \mathrm{~kg} / \mathrm{m}^{2}$ (underweight or normal/healthy weight) & 84 & 18.2 & 106 & 17.1 & 47 & 12.5 \\
\hline 25 to $\leq 29.9 \mathrm{~kg} / \mathrm{m}^{2}$ (overweight) & 134 & 29.1 & 164 & 26.5 & 109 & 29.1 \\
\hline$\geq 30 \mathrm{~kg} / \mathrm{m}^{2}$ (obese) & 242 & 52.5 & 348 & 56.2 & 218 & 58.1 \\
\hline \multicolumn{7}{|l|}{ Smoking history } \\
\hline Current or past smoker & 183 & 39.7 & 301 & 48.6 & 158 & 42.1 \\
\hline Never smoked & 263 & 57.0 & 301 & 48.6 & 202 & 53.9 \\
\hline Unknown & 15 & 3.3 & 17 & 2.7 & 15 & 4.0 \\
\hline \multicolumn{7}{|l|}{ Comorbidities $^{b}$} \\
\hline Autoimmune disease $^{c}$ & 34 & 7.4 & 91 & 14.7 & 48 & 12.8 \\
\hline Cardiovascular disease $^{\mathrm{d}}$ & 181 & 39.3 & 256 & 41.4 & 153 & 40.8 \\
\hline Malignancy & 45 & 9.8 & 74 & 12.0 & 44 & 11.7 \\
\hline Metabolic disease $^{e}$ & 92 & 20.0 & 123 & 19.9 & 69 & 18.4 \\
\hline Musculoskeletal disease $^{\mathrm{f}}$ & 97 & 21.0 & 158 & 25.5 & 88 & 23.5 \\
\hline Psychiatric disorder ${ }^{\mathrm{g}}$ & 96 & 20.8 & 150 & 24.2 & 88 & 23.5 \\
\hline COPD & 18 & 3.9 & 15 & 2.4 & 11 & 2.9 \\
\hline
\end{tabular}

IBD inflammatory bowel disease, COPD chronic obstructive pulmonary disease, $B M I$ body mass index

${ }^{a}$ Weights between 80 and 500 pounds and heights between 40 and 80 inches were used when calculating BMI to remove extreme data outliers which may signal data entry error

${ }^{\mathrm{b}}$ Comorbidities that were omitted because of small patient counts include gastrointestinal disease, neurologic disease(fibromyalgia), renal disease (chronic kidney disease), others (sleep apnea, uveitis, erectile dysfunction)

${ }^{c}$ Includes celiac disease, rheumatoid arthritis, ulcerative colitis, inflammatory bowel disease, Crohn's disease, indeterminate colitis, psoriatic arthritis, lupus

${ }^{\mathrm{d}}$ Includes cardiovascular diseases other than atherosclerosis, angina, congestive heart failure

eIncludes obesity, diabetes mellitus, hyperlipidemia

${ }^{\mathrm{f}}$ Includes osteoporosis, osteoarthritis

Includes anxiety, depression, alcoholism 
Table 2 Severity of psoriasis at baseline in the study cohorts

\begin{tabular}{|c|c|c|c|c|c|c|}
\hline \multirow[t]{2}{*}{ Baseline characteristics } & \multicolumn{2}{|c|}{$\begin{array}{l}\text { Guselkumab cohort } \\
(n=461)\end{array}$} & \multicolumn{2}{|c|}{$\begin{array}{l}\text { Secukinumab cohort } \\
(n=619)\end{array}$} & \multicolumn{2}{|c|}{$\begin{array}{l}\text { Ixekizumab cohort } \\
(n=375)\end{array}$} \\
\hline & $n$ & $\%$ & $n$ & $\%$ & $n$ & $\%$ \\
\hline \multicolumn{7}{|l|}{$P G A$ score } \\
\hline$n$ & 342 & & 480 & & 291 & \\
\hline Mean (SD) & $3.1(0.7)$ & & $3.1(0.7)$ & & $3.3(0.7)$ & \\
\hline Median (IQR) & $3(0)$ & & $3(1)$ & & $3(1)$ & \\
\hline Min-Max & $0-4$ & & $0-4$ & & $0-4$ & \\
\hline \multicolumn{7}{|l|}{$P G A$ score category } \\
\hline 0 or 1 & 12 & 2.6 & 16 & 2.6 & 6 & 1.6 \\
\hline 2 & 19 & 4.1 & 32 & 5.2 & 17 & 4.5 \\
\hline 3 & 237 & 51.4 & 305 & 49.3 & 158 & 42.1 \\
\hline 4 & 74 & 16.1 & 127 & 20.5 & 110 & 29.3 \\
\hline Unknown & 119 & 25.8 & 139 & 22.5 & 84 & 22.4 \\
\hline \multicolumn{7}{|l|}{$B S A$} \\
\hline$n$ & 442 & & 584 & & 356 & \\
\hline Mean (SD) & $23.1(20.2)$ & & $22.3(19.9)$ & & $24.8(19.6)$ & \\
\hline Median (IQR) & $16(20)$ & & $15(20)$ & & $20(24.5)$ & \\
\hline Min-Max & $1-95$ & & $0-95$ & & $0-97$ & \\
\hline
\end{tabular}

$P G A$ Physician global assessment, $B S A$ body surface area, $S D$ standard deviation, IQR interquartile range

\section{DISCUSSION}

This study describes the characteristics of psoriasis patients initiating treatment with three biologics: guselkumab, secukinumab, or ixekizumab in the USA. Although previous realworld studies have explored treatment patterns among this patient population $[19,20,22,24,25]$, this study describes patients across all three treatment cohorts, leveraging a dermatology-specific EMR platform, which provides comprehensive clinical information including disease severity measures and BMI, captured at the point-of-care by dermatology providers.

This study characterizes adults with moderate-to-severe psoriasis initiating one of the three biologics of interest in routine clinical practice. The median age of patients was 51-52 years, and most patients were 45-64 years of age, similar to published reports $[20,25]$. The majority of patients were white, as aligned with the 2010 National Health and Nutrition Examination Survey findings, which demonstrated higher prevalence of psoriasis in Caucasians [26]. Nearly $45-55 \%$ of patients were from the south, consistent with other real-world studies showing a high volume of dermatological practices in the southern region of the USA [27-29].

In the current study, over half of the study population was obese and over one-quarter overweight; this is consistent with a recent realworld study of 180 patients with moderate-tosevere psoriasis treated with guselkumab in the Corrona Psoriasis Registry, where $56 \%$ of patients were obese and just under 30\% were overweight [30]. Furthermore, a meta-analysis 

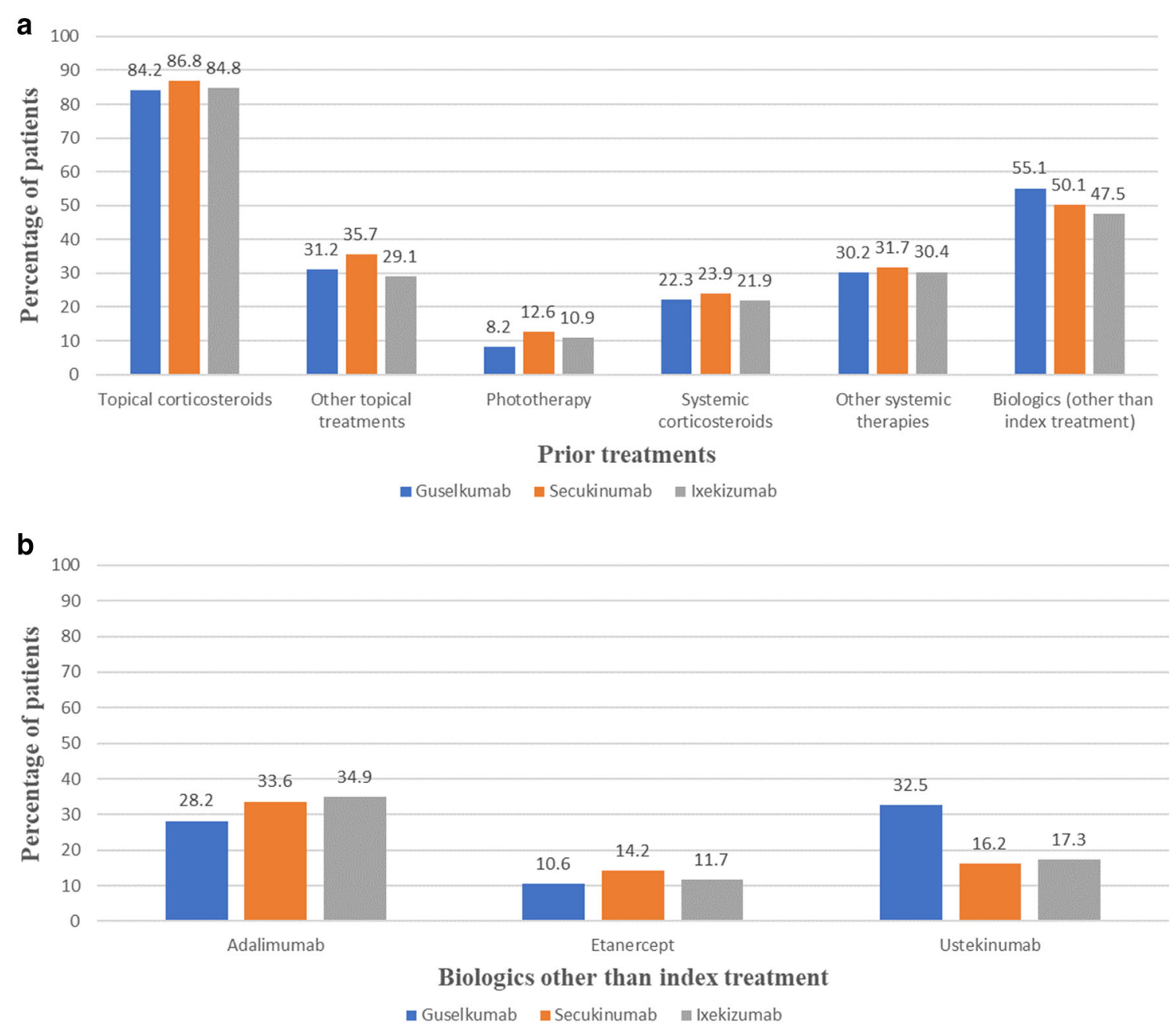

Fig. 2 a Prior treatments of the patient population at baseline in study cohorts. $\mathbf{b}$ Prior use of biologics other than index treatment at baseline in study cohorts

of cross-sectional and case-control studies suggested that patients with psoriasis have over $50 \%$ increased odds of being obese than the general population; the pooled odds ratio for obesity was higher in psoriasis patients with moderate-to-severe disease $[2.23 ; 95 \%$ confidence interval (CI), 1.63-3.05] compared with mild disease (1.46; 95\% CI, 1.17-1.82) [31]. Evidence suggests that BMI may affect early clinical response to some systemic therapies. For example, in one recent study, obese patients had approximately $30 \%$ lower odds of achieving PASI of at least $75 \%$ at follow-up (PASI-75) compared with the normal weight group at 8 weeks [32].
The findings of the current study support prior literature that patients with moderate-tosevere psoriasis have a high prevalence of comorbid conditions such as cardiovascular disease, psychiatric disorders, and metabolic disease. For example, evidence suggests a significant association between psoriasis and increased incidence of major adverse cardiovascular events [33]. Additionally, patients with psoriasis have increased prevalence of independent risk factors for cardiovascular disease, including obesity, hypertension, smoking, dyslipidemia, and insulin resistance [34]; as noted previously, over half of patients in the present study were obese and at least $40 \%$ were current or past smokers in each treatment cohort. In a 
real-world analysis, the most common comorbidities reported among psoriasis patients initiated on secukinumab were hypertension $(43.2 \%)$, hyperlipidemia $(33.9 \%)$, and anxiety (20.3\%) [2]. Furthermore, a claims database study comparing treatment patterns between ixekizumab and secukinumab users reported hypertension, hyperlipidemia, and obesity as the most commonly observed comorbid conditions [20]. Incidence of psychiatric disorders among this population has ranged from $17 \%$ to $21 \%[2,35]$, consistent with our finding of $20-24 \%$ of psoriasis patients having evidence of a psychiatric disorder. Studies have suggested that psoriasis has a strong psychological impact due to its visibility and chronic and relapsing course, leading to high stress levels, anxiety, and depressive symptoms [36, 37].

In the current real-world analysis, we found that the majority of patients had inadequate response to previous treatments prior to initiation of biologics of interest, and therefore had high PGA and BSA scores at baseline. Nearly $84 \%$ of patients across all treatment cohorts were previously treated with topical corticosteroids, consistent with the joint AAD-NPF 2020 treatment guidelines [38]. In a real-world study conducted in the USA, nearly $60 \%$ of patients with moderate-to-severe psoriasis who were on biologic therapy were prescribed concomitant topical corticosteroids [22]; systemic corticosteroids were the most common nonbiologic systemic therapy, with about one-quarter of patients having prior use, followed closely by methotrexate, which is consistent with a recent real-world study [20]. Similar to prior reports, previous exposure to biologic therapies was also high across all treatment cohorts, at around $50 \%[25,30]$. In one study, comparison of realworld treatment patterns among psoriasis patients treated with ixekizumab or adalimumab revealed a higher rate of prior use of biologics in ixekizumab users compared with adalimumab users (65.8\% versus $35.8 \%$ ) [20]. In the current study, a substantially higher proportion of guselkumab users had prior use of biologics (55\%) compared with ixekizumab and secukinumab users; this could be attributed to recent Food and Drug Administration (FDA) approval of guselkumab, as compared with secukinumab and ixekizumab [39].

Interpretation of the results should consider the study limitations. First, the MMDS database contains only data captured from physicians and other provider staff using the EMR; patient data, including prior treatments and comorbidities, taken by health care providers outside of the MMDS affiliate Electronic Medical Assistant system will not be captured. To that end, non-dermatology conditions in MMDS are selfreported and therefore may be underreported and/or discordant with medical record documentation by a provider [40]. Also, the results of this study are specific to guselkumab, secukinumab, and ixekizumab users and are not generalizable to patients receiving other biologics for psoriasis and the broader psoriasis population eligible for biologics; for instance, patients whose race was underrepresented. Also, more than $50 \%$ of patients in this study were from the Southeastern USA. This observation is consistent with the higher distribution of dermatology practices in the south [27-29]; therefore, the psoriasis patient population in other regions of the USA are underrepresented. In addition, the observed prevalence of obesity is consistent with past studies [7, 30]. It is worth noting that these studies also had a similar psoriasis population in terms of geography (e.g., south), which may have had an impact on this observation [41].

\section{CONCLUSION}

This real-world study elucidates the characteristics of moderate-to-severe psoriasis patients initiating treatment with guselkumab, secukinumab, and ixekizumab. The results suggest that over $80 \%$ of patients treated with these biologics are overweight or obese, and approximately $40-50 \%$ are current or past smokers. Correspondingly, a high prevalence of cardiovascular disease was observed. Overall, this realworld study adds to the body of literature describing the characteristics of patients with moderate-to-severe psoriasis receiving biologic treatments. 


\section{ACKNOWLEDGEMENTS}

Funding. This study and Rapid Service Fees were funded by Janssen Scientific Affairs.

Medical Writing. Paranjoy Saharia and Dr. Kavitha Ganesha from IQVIA India provided writing and editorial assistance for the manuscript. This was funded by Janssen Scientific Affairs.

Authorship. All named authors meet the International Committee of Medical Journal Editors (ICMJE) criteria for authorship for this article, take responsibility for the integrity of the work as a whole, and have provided their approval for the publication.

Author Contributions. All authors were involved in the study conception and design of the work. Aimee Near and Hyunchung Kim conducted the material preparation, data collection and analysis. All authors reviewed and revised the manuscript for important intellectual content.

Disclosures. Timothy Fitzgerald, Amanda Teeple, Mobolaji Olurinde and Katelyn Rowland are employees of Janssen Scientific Affairs; Aimee Near is an employee of IQVIA; Hyunchung Kim was an employee of IQVIA at the time of the study; IQVIA was paid by Janssen to conduct the research study.

Compliance with Ethics Guidelines. This study was based on secondary, de-identified data which comply with the Health Insurance Portability and Accountability Act (HIPAA). Institutional review board approval was not required for this study.

Data Availability. The datasets generated during and/or analyzed during the current study are not publicly available due to privacy restrictions.

Open Access. This article is licensed under a Creative Commons Attribution-NonCommercial 4.0 International License, which permits any non-commercial use, sharing, adaptation, distribution and reproduction in any medium or format, as long as you give appropriate credit to the original author(s) and the source, provide a link to the Creative Commons licence, and indicate if changes were made. The images or other third party material in this article are included in the article's Creative Commons licence, unless indicated otherwise in a credit line to the material. If material is not included in the article's Creative Commons licence and your intended use is not permitted by statutory regulation or exceeds the permitted use, you will need to obtain permission directly from the copyright holder. To view a copy of this licence, visit http://creativecommons.org/licenses/by$\mathrm{nc} / 4.0 /$.

\section{REFERENCES}

1. Korman NJ. Management of psoriasis as a systemic disease: what is the evidence? $\mathrm{Br} \mathrm{J}$ Dermatol. 2020;182(4):840-8.

2. Strober BE, Germino R, Guana A, Greenberg JD, Litman $\mathrm{HJ}$, Guo N, et al. US real-world effectiveness of secukinumab for the treatment of psoriasis: 6-month analysis from the Corrona Psoriasis Registry. J Dermatolog Treat. 2020;31(4):333-41.

3. Menter A, Strober BE, Kaplan DH, Kivelevitch D, Prater EF, Stoff B, et al. Joint AAD-NPF guidelines of care for the management and treatment of psoriasis with biologics. J Am Acad Dermatol. 2019;80(4): 1029-72.

4. Rendon A, Schakel K. Psoriasis pathogenesis and treatment. Int J Mol Sci. 2019;20(6):1475.

5. Aurangabadkar SJ. Comorbidities in psoriasis. Indian J Dermatol Venereol Leprol. 2013;79(Suppl 7):S10-7.

6. Setty AR, Curhan G, Choi HK. Obesity, waist circumference, weight change, and the risk of psoriasis in women: Nurses' Health Study II. Arch Intern Med. 2007;167(15):1670-5.

7. Armstrong AW, Harskamp CT, Armstrong EJ. The association between psoriasis and obesity: a systematic review and meta-analysis of observational studies. Nutr Diabetes. 2012;2: e54. 
8. Wong Y, Nakamizo S, Tan KJ, Kabashima K. An update on the role of adipose tissues in psoriasis. Front Immunol. 2019;10:1507.

9. Vaidya TS, Feldman S, Kirk J. Patient-centered approach to biologics in the treatment of psoriasis. J Nat Sci. 2015;1:53.

10. Brownstone ND, Hong J, Mosca M, Hadeler E, Liao W, Bhutani T, et al. Biologic treatments of psoriasis: an update for the clinician. Biol Targets Therapy. 2021;15:39-51.

11. Blauvelt A, Gooderham M, Iversen L, Ball S, Zhang L, Agada NO, et al. Efficacy and safety of ixekizumab for the treatment of moderate-to-severe plaque psoriasis: results through 108 weeks of a randomized, controlled phase 3 clinical trial (UNCOVER-3). J Am Acad Dermatol. 2017;77(5): 855-62.

12. Griffiths CEM, Papp KA, Kimball AB, Randazzo B, Song M, Li S, et al. Long-term efficacy of guselkumab for the treatment of moderate-to-severe psoriasis: results from the phase 3 VOYAGE 1 trial through two years. J Drugs Dermatol. 2018;17(8): 826-32.

13. McMichael A, Desai SR, Qureshi A, Rastogi S, Alexis AF. Efficacy and safety of brodalumab in patients with moderate-to-severe plaque psoriasis and skin of color: results from the pooled AMAGINE-2/-3 randomized trials. Am J Clin Dermatol. 2019;20(2): 267-76.

14. Blauvelt A, Leonardi C, Elewski B, Crowley JJ, Guenther LC, Gooderham M, et al. A head-to-head comparison of ixekizumab vs. guselkumab in patients with moderate-to-severe plaque psoriasis: 24-week efficacy and safety results from a randomized, double-blinded trial. British J Dermatol. 2021;184(6):1047-58.

15. Griffiths CE, Reich $K$, Lebwohl M, van de Kerkhof $P$, Paul C, Menter A, et al. Comparison of ixekizumab with etanercept or placebo in moderate-to-severe psoriasis (UNCOVER-2 and UNCOVER-3): results from two phase 3 randomised trials. Lancet (London, England). 2015;386(9993):541-51.

16. Leonardi C, Reich K, Foley P, Torii H, Gerdes S, Guenther L, et al. Efficacy and safety of ixekizumab through 5 years in moderate-to-severe psoriasis: long-term results from the UNCOVER-1 and UNCOVER-2 phase-3 randomized controlled trials. Dermatol Therapy. 2020;10(3):431-47.

17. Reich K, Armstrong AW, Langley RG, Flavin S, Randazzo B, Li S, et al. Guselkumab versus secukinumab for the treatment of moderate-to-severe psoriasis (ECLIPSE): results from a phase 3, randomised controlled trial. Lancet. 2019;394(10201):831-9.

18. Warren RB, Brnabic A, Saure D, Langley RG, See K, $\mathrm{Wu} \mathrm{JJ}$, et al. Matching-adjusted indirect comparison of efficacy in patients with moderate-to-severe plaque psoriasis treated with ixekizumab vs. secukinumab. Br J Dermatol. 2018;178(5):1064-71.

19. Blauvelt A, Shi N, Burge R, Malatestinic WN, Lin $\mathrm{CY}$, Lew CR, et al. Comparison of real-world treatment patterns among psoriasis patients treated with ixekizumab or adalimumab. Patient Prefer Adher. 2020;14:517-27.

20. Blauvelt A, Shi N, Burge R, Malatestinic WN, Lin $\mathrm{CY}$, Lew CR, et al. Comparison of real-world treatment patterns among patients with psoriasis prescribed ixekizumab or secukinumab. J Am Acad Dermatol. 2020;82(4):927-35.

21. Snast I, Sherman S, Holzman R, Hodak E, Pavlovsky L. Real-life experience of guselkumab in patients with psoriasis. Dermatol Therapy. 2020;33(6): e13964.

22. Noe MH, Shin DB, Doshi JA, Margolis DJ, Gelfand JM. Prescribing patterns associated with biologic therapies for psoriasis from a united states medical records database. J Drugs Dermatol. 2019;18(8): $745-50$.

23. Armstrong AW, Foster SA, Comer BS, Lin CY, Malatestinic W, Burge R, et al. Real-world health outcomes in adults with moderate-to-severe psoriasis in the United States: a population study using electronic health records to examine patient-perceived treatment effectiveness, medication use, and healthcare resource utilization. BMC Dermatol. 2018;18(1):4.

24. Blauvelt A, Shi N, Zhu B, Burge R, Malatestinic WN, Lin CY, et al. Comparison of health care costs among patients with psoriasis initiating ixekizumab, secukinumab, or adalimumab. J Manag Care Spec Pharm. 2019;25(12):1366-76.

25. Herrera-Acosta E, Garriga-Martina GG, Suárez-Pérez JA, Martínez-García EA, Herrera-Ceballos E. Comparative study of the efficacy and safety of secukinumab vs ixekizumab in moderate-to-severe psoriasis after 1 year of treatment: Real-world practice. Dermatol Therapy. 2020;33(3): e13313.

26. Rachakonda TD, Schupp CW, Armstrong AW. Psoriasis prevalence among adults in the United States. J Am Acad Dermatol. 2014;70(3):512-6.

27. Feldman SR, Hur P, Zhao Y, Tian H, Wei Z, Wang X, et al. Incidence rates of comorbidities among patients with psoriasis in the United States. Dermatol Online J 2018;24(10). 
28. Nguyen KB, Read C, Wu KK, Armstrong AW. Where you live matters: Regional differences in health care resource use for psoriasis in the United States. J Am Acad Dermatol. 2020;82(6):1360-7.

29. Takeshita J, Gelfand JM, Li P, Pinto L, Yu X, Rao P, et al. Psoriasis in the US medicare population: prevalence, treatment, and factors associated with biologic use. J Invest Dermatol. 2015;135(12): 2955-63.

30. Armstrong AW, Callis-Duffin K, Fitzgerald T, Teeple A, Uy J, Olurinde M, et al. Effectiveness of guselkumab among patients with moderate-to-severe plaque psoriasis in the Corrona Psoriasis Registry. J Am Acad Dermatol 2021;85(3):AB122.

31. Armstrong AW, Harskamp CT, Armstrong EJ. The association between psoriasis and obesity: a systematic review and meta-analysis of observational studies. Nutr Diabet. 2012;2(12): e54.

32. Naldi L, Addis A, Chimenti S, Giannetti A, Picardo $\mathrm{M}$, Tomino C, et al. Impact of body mass index and obesity on clinical response to systemic treatment for psoriasis. Evidence from the Psocare project. Dermatology. 2008;217(4):365-73.

33. Samarasekera EJ, Neilson JM, Warren RB, Parnham J, Smith CH. Incidence of cardiovascular disease in individuals with psoriasis: a systematic review and meta-analysis. J Invest Dermatol. 2013;133(10): 2340-6.

34. Caiazzo G, Fabbrocini G, Di Caprio R, Raimondo A, Scala E, Balato $\mathrm{N}$, et al. Psoriasis, cardiovascular events, and biologics: lights and shadows. Front Immunol. 2018;9:1668.
35. Shah K, Paris M, Mellars L, Changolkar A, Mease PJ. Real-world burden of comorbidities in US patients with psoriatic arthritis. RMD Open. 2017;3(2): e000588.

36. Parafianowicz K, Sicińska J, Moran A, Szumański J, Staniszewski K, Rudnicka L, et al. Psychiatric comorbidities of psoriasis: pilot study. Psychiatr Pol. 2010;44(1):119-26.

37. Yélamos O, Ros S, Puig L. Improving patient outcomes in psoriasis: strategies to ensure treatment adherence. Psoriasis (Auckl). 2015;5:109-15.

38. Elmets CA, Korman NJ, Prater EF, Wong EB, Rupani RN, Kivelevitch D, et al. Joint AAD-NPF guidelines of care for the management and treatment of psoriasis with topical therapy and alternative medicine modalities for psoriasis severity measures. J Am Acad Dermatol. 2021;84(2):432-70.

39. CDER. Center for Drug Evaluation and Research; BLA multi-disciplinary review and evaluation BLA761061 TREMFYA (guselkumab) injection, for subcutaneous use; Janssen Biotech, Inc. 2016.

40. Corser W, Sikorskii A, Olomu A, Stommel M, Proden C, Holmes-Rovner M. Concordance between comorbidity data from patient self-report interviews and medical record documentation. BMC Health Serv Res. 2008;8(1):85.

41. CDC. Adult Obesity Prevalence Maps. https://www. cdc.gov/obesity/data/prevalence-maps.html. Accessed 24 January 2022. 